thành công khi bắt đầu thở không xâm nhập bằng phương thức AVAPS.

\section{TÀI LIẸU THAM KHẢO}

1. Gold Reports (2019). Global Initiative for Chronic Obstructive Lung Disease - GOLD. <http://goldcopd.org/gold-reports/>, accessed: 28/09/2020.

2. Schmidt M., Demoule A., Deslandes-Boutmy E. và cộng sự. (2014). Intensive care unit admission in chronic obstructive pulmonary disease: patient information and the physician's decision-making process. Crit Care, 18(3), R115.

3. Ai-Ping C., Lee K.-H., và Lim T.-K. (2005). Inhospital and 5-year mortality of patients treated in the ICU for acute exacerbation of COPD: a retrospective study. Chest, 128(2), 518-524.

4. Breen D., Churches T., Hawker F. và cộng sự. (2002). Acute respiratory failure secondary to chronic obstructive pulmonary disease treated in the intensive care unit: a long term follow up study. Thorax, 57(1), 29-33.

5. Storre J.H., Seuthe B., Fiechter R. và cộng sự. (2006). Average volume-assured pressure support in obesity hypoventilation: A randomized crossover trial. Chest, 130(3), 815-821.

6. Murphy $P_{.}$, Davidson $C_{\text {., }}$ Hind $M$. và cộng sự. (2012). Volume targeted versus pressure support non-invasive ventilation in patients with super obesity and chronic respiratory failure: $A$ randomised controlled trial. Thorax, 67, 727-34.

7. Confalonieri M., Garuti G., Cattaruzza M.S. và cộng sự. (2005). A chart of failure risk for noninvasive ventilation in patients with COPD exacerbation. Eur Respir J, 25(2), 348-355.

8. Ciftci F. (2017). Evaluation of the feasibility of average volume-assured pressure support ventilation in the treatment of acute hypercapnic respiratory failure associated with chronic obstructive pulmonary disease: A pilot study. Journal of Critical Care, 40.

9. Briones Claudett K.H., Briones Claudett M., Chung Sang Wong M. và công sứ. (2013). Noninvasive mechanical ventilation with average volume assured pressure support (AVAPS) in patients with chronic obstructive pulmonary disease and hypercapnic encephalopathy. BMC Pulm Med, 13, 12.

\title{
NHU CẦU VÀ GIẢI PHÁP PHÁT TRIỂN CÔNG ĐOÀN TẠI CƠ SỞ Y TẾ NGOÀI CÔNG LẬP
}

\section{Nguyễn Đức Hữu ${ }^{3}$}

TÓM TẮT

Mục tiêu: Mô tả thực trạng và nhu câu của người lao đông tai các cơ sở y tế ngoài công lập và giải pháp. Phương pháp: Nghiên cứu mô tả cắt ngang, sử dụng kết hợp phương pháp nghiên cứu định tính và định lượng; nghiên cứu bàn giấy kết hợp với nghiên cứu thực đia 543 người lao động ở cơ sở y tế ngoài công lập đã thành lập và chưa thành lập công đoàn tại Hà Nội, Hồ Chí Minh và Đà Nẵng. Kểt quả: năm 2019 các cơ sở Y tế ngoài công lập có xu hướng gia tăng 14,5\% so với năm 2018, nhưng chỉ có 0,65\% tổ chức công đoàn được thành lập. Số liệu thống kê cơ sở y tế ngoài công lập chưa thống nhất giữa Sở $Y$ tế và Liên đoàn Lao động. Người lao động tham gia tổ chức công đoàn được hưởng lợi nhiều hơn lao đông ở các tổ chức chưa tham gia công đoàn về bảo hiểm xã hội, bảo hiểm y tế, bảo hiểm tai nạn và Phụ cấp đô̂c hại, phụ cấp trách nhiệm. Đặc biệt cơ sở đã thành lập công đoàn thì trang thiết bị bảo hộ

${ }^{1}$ Công đoàn Y tế Việt Nam

${ }^{2}$ Nghiên cứu viên Viện Chiến lược và Chính sách Y tế

${ }^{3}$ Trường Đại học Công đoàn

"Viện Công nhân và Công đoàn

Chịu trách nhiệm chính: Phạm Thanh Bình

Email: thanhbinhpham123456@gmail.com

Ngày nhận bài: 3.3.2021

Ngày phản biện khoa học: 26.4.2021

Ngày duyệt bài: 7.5.2021
Phạm Thanh Bình' ${ }^{1}$ Hoàng Thị Mỹ Hạnh², Nguyễn Thanh Tùng ${ }^{4}$, Trần Thị Thu Hiền ${ }^{1}$ đây đủ có tỷ lệ $65,8 \%$ cao hơn so với tổ chức y tê ngoài công lập chưa thành lập công đoàn chỉ đạt $46,7 \%$. Các đối tượng được phỏng vấn có $74.9 \%$ mong muốn các tổ chức đại diện người lao động bảo vệ tốt hơn cho người lao động; 71,9\% cho biết họ không muốn có tổ chức đại diện người lao động không thuộc hệ thống công đoàn trong các cơ sở y tế ngoài công lập; còn lại 22,7\% chưa biết lập trường, quan điểm của mình. Về phương pháp tâp hợp đoàn viên thì trên $70 \%$ người được hỏi cho rằng phải kết hợp hai phương pháp từ dưới lên và từ trên xuống. Kểt luận: đổi mới phương thức tập hợp người lao đông ở cơ sở y tế ngoài công lập là yêu cầu cấp bách đối với các cấp công đoàn.

Tư khóa: Công đoàn cơ sở (CĐCS), Cơ sở y tế ngoài công lập (CSYTNCL), tập hợp đoàn viên; Đổi mới phương thức, CPTPP; EVFTA; Công đoàn ghép; Kết hợp phương thức cũ và mới.

\section{SUMMARY \\ NEEDS AND SOLUTIONS FOR TRADE UNION DEVELOPMENT IN NON-PUBLIC HEALTHCARE INSTITUTIONS}

Objective: The paper describes the current situation and needs of workers in non-public healthcare facilities as well as solutions. Method: This study employs a cross-sectoral descriptive design with a combination of quantitative and qualitative research; Desk research combined with field research of 543 workers in non-public healthcare with and 
without trade unions in Hanoi, Ho Chi Minh, and Da Nang. Result: In 2019, non-public health facilities tended to increase by $14.5 \%$ compared to 2018 , but only $0.65 \%$ of trade unions were established in those facilities. Statistics of non-public health facilities are inconsistent with the Department of Health and the Confederation of Labor. Employees participating in trade unions benefit more than workers not from unions in terms of social insurance, health insurance, accident insurance, hazardous allowance, and liability allowance. In particular, healthcare establishments with trade unions provide more protective equipment at $65.8 \%$, compared to those without trade unions, at $46.7 \%$. Regarding interviewed subjects, $74.9 \%$ want workers' representative organizations to perform better protection to workers; $71.9 \%$ said that they do not want to have a representative organization of workers who are not part of the trade union system in the non-public medical facilities; The remaining $22.7 \%$ do not know their stance of view. Regarding methods of reuniting members, over $70 \%$ of respondents said that it is necessary to combine two methods the bottom-up and the top-down. Conclusion: The new method of gathering workers in non-public health facilities is an urgent requirement for trade unions at all levels.

Keyword: local trade unions, non-public healthcare facilities, method innovation, CPTPP, EVFTA, trade union merger, old and new methods combinat

\section{I. ĐăT VẤN ĐỀ}

Tính đến cuối năm 2018, cả nước đã có hơn 240 bệnh viện tư, hơn 35000 phòng khám đa khoa chuyên khoa tư nhân; lĩnh vực cả nước có 66,910 cơ sở bán lẻ; 4828 cơ sở bán buôn và 380 cơ sở sản xuất, xuất nhập khẩu dược phẩm. Ước tính khoảng 250 ngàn cán bộ y tế thuộc lĩnh vực ngoài công lập, bằng khoảng $50 \%$ cán bộ $y$ tể ở lĩnh vực công. Y tế công lập và ngoài công bình đẳng trước pháp luật; $Y$ tế ngoài công lập cũng tham gia phòng chống dịch và có vai trò an sinh xã hội và thực hiện nhiệm vụ chính trị của ngành y tế khi được huy động. Nhất là giai đoan chống dịch COVID-19 vừa qua có thể khẳng định, sức khỏe và sự an toàn, nhất an toàn vệ sinh lao động của lực lượng y tế là nguồn lực quốc gia, nếu nguồn lực này, cả y tế công lập và ngoài công lập không được chỉ đạo hoạt động thống nhất sẽ ảnh hưởng đến đến an sinh xã hội và kinh tế chính trị của đất nước.

Tuy nhiên, $x u$ hướng cán bộ y tế công chuyển việc sang cung cấp dịch vụ y tế tư nhân ngày càng gia tăng; cán bộ y tế vừa làm công, vừa làm tư làm mối quan hệ lao động khu vực ngoài công lập khó quản lý. Việt Nam đã và đang hiện thực hóa các cam kết Hiệp định CPTPP và Hiệp định EVFTA thông qua Bộ luật Lao động năm 2019, theo đó người lao động được thành lập "tổ chức đại diện của người lao động" mà không cần phải có sự ủy quyên trước từ bất kỳ tổ chức hay cá nhân nào. Việc phải tham gia trong hệ thống CĐVN không còn là một nghĩa vu của tổ chức đại diên cho người lao động/công đoàn cơ sở nữa. Nhận thức của các đối tượng cán bộ y tế ngoài công lập về tổ chức công đoàn và tổ chức đại diện chưa cao nên tỷ lệ cán bộ y tế ngoài công lập tham gia tổ chức công đoàn thấp. Chưa có nghiên cứu về thực trạng lao động, quan hệ lao động, phương thức thu hút đoàn viên tham gia công đoàn cũng như nhu cầu tham gia công đoàn của người lao động trong các cơ sở y tế ngoài công lập. Do đó, đề tài Đổi mới phương thức tập hợp người lao động tham gia tổ chức Công đoàn giai đoạn thực hiện CPTPP, EVFTA là hết sức cần thiết.

\section{II. ĐỐI TƯỢNG VÀ PHƯƠNG PHÁP NGHIÊN CỨU}

1.Đối tượng, địa điểm và thời gian nghiên cứu: Xuất phát từ thực tế trên chúng tôi tiến hành nghiên cứu đề tài tại 3 TP: Hồ Chí Minh, Hà Nội, Đà Nẵng với 543 người lao động ở cơ sở y tế ngoài công lập (đã thành lập công đoàn và chưa thành lập) từ tháng 6-9/2020. 543 người lao động làm tại 24 cơ sở y tế tư nhân, gồm 178 người làm việc tại bệnh viện; 290 người làm việc tại các phòng khám đa khoa và chuyên khoa; 60 người làm ở các doanh nghiệp và 15 người làm ở các loại hình cơ sở y tế tư nhần khác.

\section{Phương pháp nghiên cứu:}

2.1. Thiết kế nghiên cứu: Nghiên cứu dịch tễ học mô tả cắt ngang; kết hợpđiều tra định tính (phòng vấn sâu, thảo luận nhóm) và định lượng (thống kê và xử lý số liệu điều tra).

2.2. Cỡ mẫu và chọn mẫu nghiên cứu: Cõ̃ mẫu người lao động mỗi nhóm cần khảo sát được tính theo công thức tính cỡ mẫu một tỷ lệ

$$
n=Z_{(1-\alpha / 2)}^{2} \cdot \frac{p(1-p)}{d^{2}}
$$

Trong đó: n: số người lao động được khảo sát; z: Hệ số tin cậy. Với độ tin cậy 95\% thì giá trị của $z=1,96 ; p$ : tỷ lệ người lao động hài lòng với hoạt động của công đoàn cơ sở có nhu cầu tham gia công đoàn/tố chức đại diện cho người lao động ở cơ sở; $q=1-p=0,5 ; d$ : sai số chấp nhân, chọn $\mathrm{d}=0,08 ; \mathrm{DE}=1.5 ;$ Tỷ lệ từ chối/phiếu không hoàn thành: $5 \%$. Áp dụng công thức trên, cỡ mẫu nhóm đã thành lập cổng đoàn là 240 người, mỗi tỉnh 80 người chon có chủ đích cho từng loại hình cơ sỏ y tế ngoài công lập; đối tượng chưa thành lập công đoàn cơ sở làm tròn là 315 người lao động, mỗi tỉnh chọn 105 ngẫu nhiên ở 15 đơn vị (phương pháp chọn mẫu nhiều giai đoạn); 


\section{KẾT QUẢ NGHIÊN CỨU}

Theo thống kê của Sở $Y$ tế các tỉnh/thành phố, tính đến cuối năm 2019, tại 22 tỉnh thành phố đã có trên 31,050 cơ sở y tế ngoài công lập, trong đó có 82 bệnh viện; 12,084 phòng khám và 18,884 doanh nghiệp hoạt động trong lĩnh vực y tế. Do với cuối năm 2018, số lượng cơ sở y tế ngoài công lập tại các tính được thống kê đã tăng lên $14,5 \%$. Tuy nhiên, theo thống kê của 39 Liên đoàn Lao động tỉnh thành phố, tỷ lệ cơ sở y tế ngoài công lập thành lập công đoàn chiếm chỉ 1,3\% (670/51.290) năm 2019.

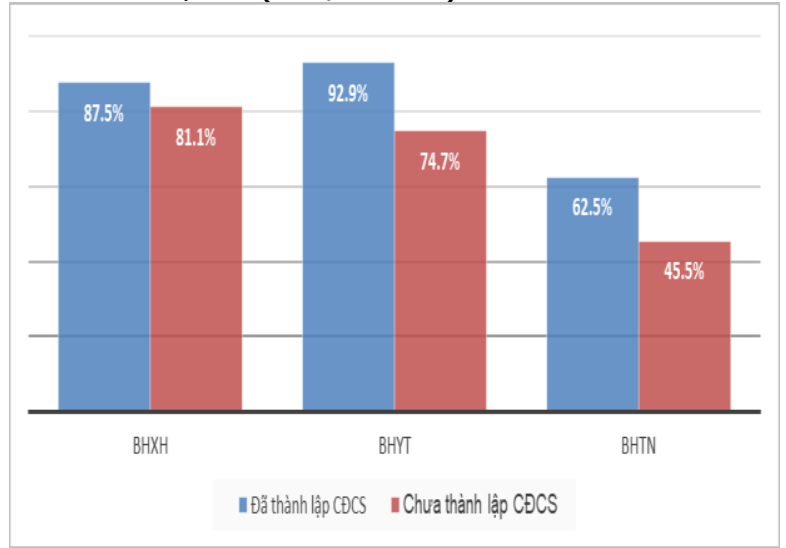

Biểu đồ 1: Tình hình tham gia các loại bảo hiểm của người lao động, phân theo tình trang thành lập CĐCS

Phân tích 543 người lao động được điều tra tại 3 tỉnh với đối tượng tại cơ sở ngoài công lập đã thành lập công đoàn và chưa thành lập công đoàn thì quyên lợi của người thham gia công đoàn cao hơn đối tượng chưa tham gia về bảo hiểm xã họi, bảo hiểm y tế và bảo hiểm tai nạn (Xem biểu đồ 1). Cao nhất là tỷ lệ tham gia bảo hiểm y tế $92,9 \%$ cao hơn $74,7 \%$ ở các đơn vị chưa tham gia tổ chức công đoàn.

Người tham gia tổ chức công đoàn ở cơ sở y tế ngoài công lập thì được trang bị bảo hộ lao động đầy đủ hơn $65,8 \%$ so với $46,7 \%$ ở các cơ sở y tế chưa tham gia công đoàn (Xem biểu đồ 2).

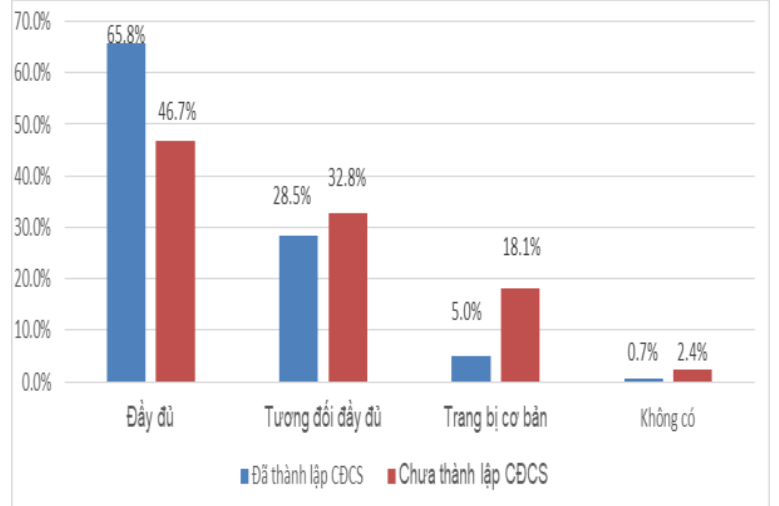

Biểu đồ 2: So sánh mức độ trang bi bảo hộ lao động trong các cơ sở y tế ngoài công lập Người lao động tham gia công đoàn, ngoài lương thì tiền chuyên cần, tiền phụ cấp, tiền độc hại cao hơn ở các cơ sở y tế chưa có tổ chức cổng đoàn (Xem biểu đồ 3). Cao nhất là tiền độc hại $41,6 \%$ so với $5,49 \%$.

Biểu đồ 3: So sánh các khoản thu nhập ngoài lương của người lao động, phân theo đơn vị có công đoàn và đớn vị chưa có công đoàn

mã thành lập CĐCS 도 Chưa thành lập CĐCS

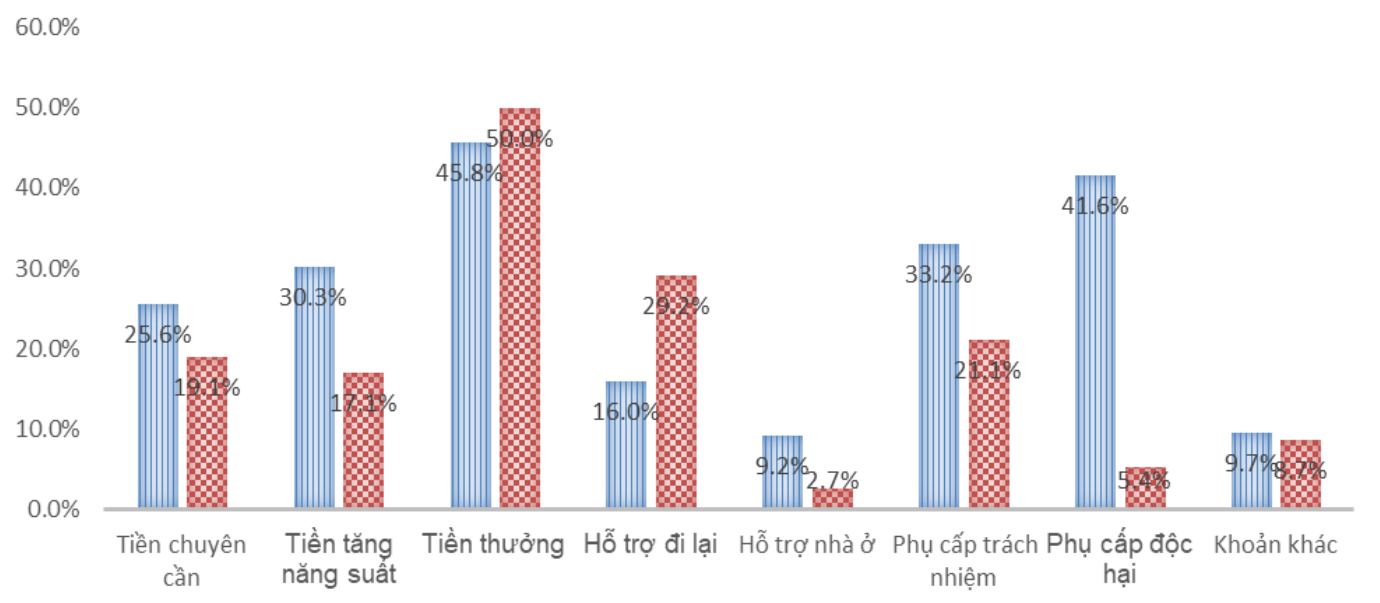

Kết quả khảo sát ở đơn vị chưa thành lập công đoàn cho thây, có $64,5 \%$ cho biết họ không mong muốn thành lập tổ chức đại diện người lao động trong đơn vị mình đang lam việc (Xem biểu đồ 4). 


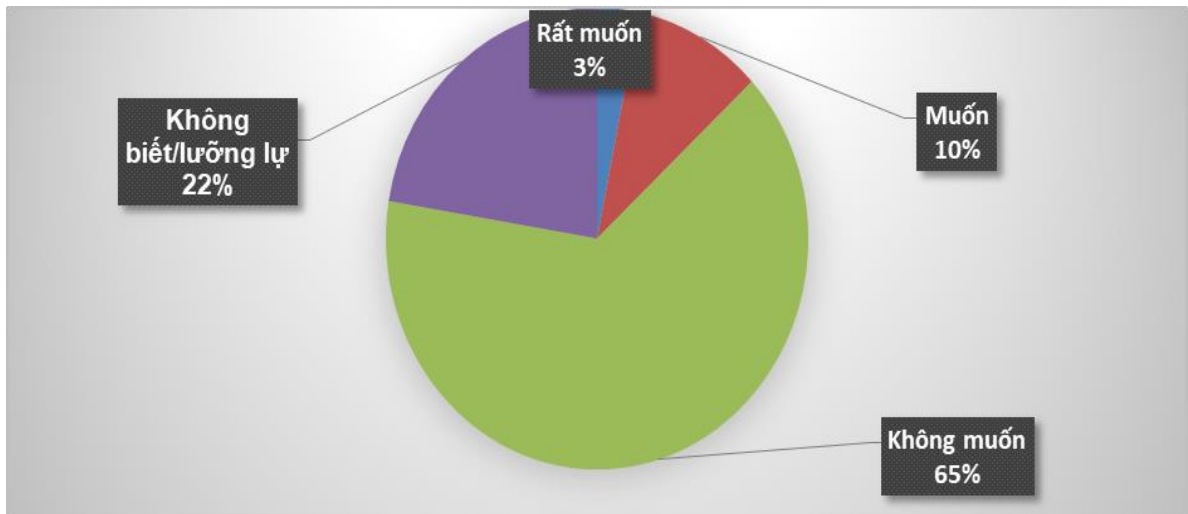

Biểu đồ 4: Mong muốn thành lập tổ chức đại diện người lao động trong các cơ sở y tếngoài công lập Tỷ lệ trung bình $72,5 \%$ muốn thành lập tỏ chức công đoàn theo hình thức kết hợp phương pháp truyền thống và phương pháp mới (xem bảng 1 )

Bảng 3: Các hình thức vận động thành lập công đoàn cơ sở theo mô hình hoạt động của các cơ sở y tếngoài công lập

\begin{tabular}{|c|c|c|c|c|}
\hline Cách thức vận động & $\begin{array}{c}\text { Phòng } \\
\text { khám }\end{array}$ & $\begin{array}{c}\text { Bệnh } \\
\text { viện }\end{array}$ & $\begin{array}{c}\text { Doanh } \\
\text { nghiệp }\end{array}$ & $\begin{array}{c}\text { Tỷ lệ } \\
\text { chung }\end{array}$ \\
\hline $\begin{array}{c}\text { Công đoàn cấp trên tiếp cận NSDLĐ và đề } \\
\text { nghị thành lập công đoàn cơ sở }\end{array}$ & $12.9 \%$ & $50.0 \%$ & $31.6 \%$ & $18.0 \%$ \\
\hline $\begin{array}{c}\text { Công đoàn cấp trên tiếp cận và vận động NLĐ } \\
\text { tự nguyện thành lập công đoàn cơ sở }\end{array}$ & $9.8 \%$ & $10.0 \%$ & $0.0 \%$ & $9.5 \%$ \\
\hline Kết hợp cà 2 hình thức trên & $77.3 \%$ & $40.0 \%$ & $68.4 \%$ & $72.5 \%$ \\
\hline
\end{tabular}

Kết quả khảo sát cho thấy, mặc dù đơn vị chưa có tổ chức CĐCS, nhưng đã có $87,2 \%$ người lao động tham gia khảo sát đã từng nghe nói đến tổ chức công đoàn, nhưng nhận thức về tổ chức công đoàn thì chỉ 12,8\% (Xem biểu đồ 5)

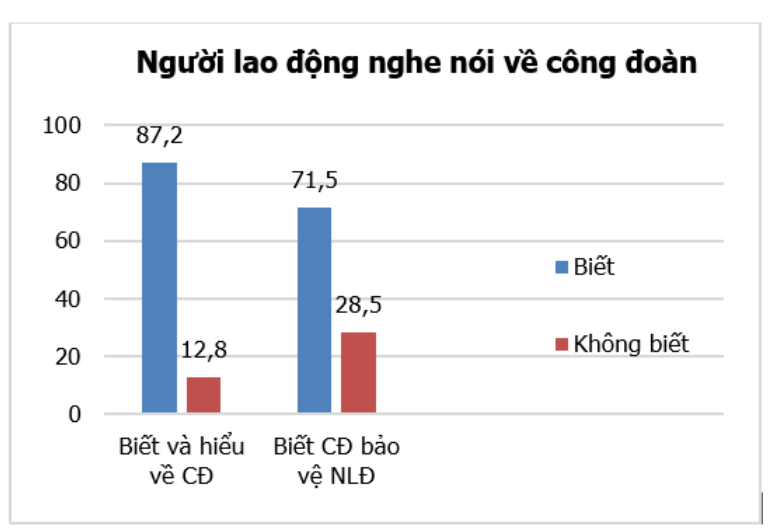

Biểu đồ 5: So sánh giữa Biết và Nhận thức của NLE về công đoàn trong đơn vị chưa có CĐCS

\section{BÀN LUÂNN}

Một đặc trưng cơ bản của các Hiệp định tự do thương mại thế hệ mới đó là đưa những tiêu chuẩn rất mới gắn với quyền con người với các vấn đề xã hội và vấn đề quản trị quốc gia đưa vào hiệp định. Việt Nam đã cam kết thể hiện cụ thể hóa tại Điều 170, Bộ luật Lao động năm 2019, có hiệu lực thi hành từ 01/01/2021 về quyền thành lập, gia nhập và tham gia hoạt động của tổ chức đại diện người lao động tại cơ sở, cho phép người lao động tại một doanh nghiệp được thành lập "tổ chức đại diện của người lao động" mà không cần phải có sự ủy quyền trước từ bất kỳ tổ chức hay cá nhân nào.

Cơ sở y tế ngoài công lập gia tăng 14,5\%/ năm, số lượng CĐCS trong các cơ sở y tế ngoài công lập đã tăng lên $11,3 \%$, tỷ lệ cơ sở y tế ngoài công lập tham gia công đoàn rất thấp $1,9 \%$. Khảo sát cho thấy $65 \%$ họ không muốn tham gia tổ chức người lao động mới, đây là một thuận lợi cho tổ chức Công đoàn Việt Nam. $72,5 \%$ người lao động mong muốn kết nạp vào tổ chức công đoàn bằng cả hai phương thức kết hợp cả phương thức cũ và mới. Thực tế đã chứng minh lý do họ muốn tham gia tổ chức công đoàn Việt Nam là có lợi hơn so với không tham gia tổ chức công đoàn tại các biểu đồ $1,2,3$ về các chế độ bảo hiểm xã hội, bảo hiểm y tế, bảo hiểm tai nạn và đặc biệt là trang thiết bị bảo hộ và chế độ độc hại.

Như vậy, tập hợp lực lượng lao động tại các cớ sở y tế ngoài công lập là một mục tiêu cấp bách, không chỉ có ý nghĩa đảm bảo lực lượng 
đảm bảo chính trị xã hội cho 97 triệu dân, lực lương này tham gia công đoàn sẽ là một kênh giúp các cơ quan nhà nước giám sát được chất lượng dịch vụ y tế.

Giải pháp để tập hợp được lực lương này chính là giải pháp đồng bộ về vắn bản,hướng dẫn của Tổng liên đoàn về việc tập hợp theo phương pháp kết hợp cũ và mới. Tại 670 công đoàn cơ sở năm 2019 là 51.290 người (đạt trung bình 77 đoàn viên công đoàn/01 CĐCS), trên thực tế người lao động trong các cơ sở ngoài công lập qua thảo luận nhóm và phỏng vấn sâu rất ít 90\% là dưới 25 đoàn viên, họ mong muốn thành lập các công đoàn ghép theo các lînh vực chuyên khoa của ngành. Hiện nay mô hình công đoàn ghép này cũng chưa có hướng dẫn của Tổng liên đoàn, cần được thí điểm mô hình để nhẩn rộng.

Thứ hai về công tác tuyên truyền $87,2 \%$ người lao động tham gia khảo sát đã từng nghe nói đến tổ chức công đoàn, nhưng nhận thức về tổ chức công đoàn thì chỉ $12,8 \%$, do đó tuyên truyền cho đối tượng lao động cần được quan tâm đầu tiên để hiểu biết đầy đủ về hệ thống công đoàn, từ đó ho mới có mong muốn tham gia, thành lập ban vận động. Không chỉ có người lao động, người sử dụng lao động cũng cần hiểu biết đầy đủ về quyền, nghĩa vụ và trách nhiệm của chủ sử dung lao động.

Thứ ba, cần có sự chỉ đạo thống nhất của cấp ủy đảng các địa phương doanh nghiệp, kết hợp với cơ quan quản lý nhà nước về y tế tại địa phương để nắm bắt chính sách các cơ sở được cấp phép hoạt động để có kế hoạch phối hợp tuyên truyền vận động tham gia tổ chức công đoàn Viêt Nam. Ngoài ra, lĩnh vức y tế đặc thù có rất nhiều hội nghể nghiêp tại địa phương, thông qua hội này là một kênh tuyên truyền để người lao động ở cơ sở ngoài công lập tham gia tổ chức công đoàn và phối hợp bảo vệ người lao động.

\section{KẾT LUÂ̂N}

1. Cơ sở y tế ngoài công lập gia tăng $14,5 \% /$ năm, số lượng CĐCS trong các cơ sở y tế ngoài công lập đã tăng lên $11,3 \%$, nhưng tỷ lệ cơ sở y tế ngoài công lập tham gia công đoàn rất thấp $1,9 \%$.

2. Nhận thức về tổ chức công đoàn chưa đầy đủ, $87,2 \%$ người lao động tham gia khảo sát đã từng nghe nói đến tổ chức công đoàn, nhưng nhận thức về tổ chức công đoàn thì chỉ 12,8\%

3. So sánh giữa người lao động tại cơ sở có công đoàn thì các chế độ bảo hiểm xã hội, bảo hiểm y tế, bảo hiểm tai nạn và đặc biệt là trang thiết bị bảo hộ và chế độ độc hại cao hơn không tham gia tổ chức công đoàn.

4. Khảo sát cho thấy $65 \%$ người lao động không muốn tham gia tổ chức người lao động mới, đây là một thuận lợi cho tổ chức Công đoàn Việt Nam. 72,5\% người lao động mong muốn kết nạp vào tổ chức công đoàn bằng cả hai phương thức kết hợp cả phương thức cũ và mới.

Nghiên cứu chỉ ra việc tập hợp người lao động ở cơ sở y tế ngoài công lập là yêu câu cấp bách và cần phải đổi mới phưởng thức tập hợp theo hướng công đoàn ghép các lînh vực chuyển ngành; kết hợp với hội nghề nghiệp, cơ quan quản lý dưới sự chỉ đạo của cấp ủy để tập hợp người lao động tham gia tổ chức công đoàn; cần kết hợp cả hai phương pháp tập hợp truyền thống và phương pháp mới.

\section{KHUYẾN NGH!}

- Tổng LĐLE có văn bản hướng dẫn đầy đủ, đồng bộ về phương thức tập hợp lî̀ng ghép mới và cũ; hướng dẫn về thành lập công đoàn cơ sở ghép; Tăng cường tuyên truyền đầy đủ cho cho người lao động, người sử dụng lao động; Đào tạo cho đội ngũ cán bộ công đoàn cấp trên chuyên nghiệp để hướng dẫn ban vận động

- Xây dựng kế hoạch tổng thể và giao chỉ tiêu thành lập công đoàn cơ sở y té ngoài công lập cho LĐLĐ, CĐN y tế tỷ lệ hàng năm.

- Chỉ đạo công đoàn các cấp phối hợp với hội nghề nghiệp, cơ quan quản lý hành nghề địa phương dưới sự chỉ đạo của cấp ủy để tập hợp người lao động tham gia tổ chức công đoàn

\section{TÀI LIỆ THAM KHẢO}

1. Jacques Bourgeois, WilmerHale và Trường cao đẳng Châu Âu (2013): Một phân tích so sánh về các quy định được lựa chọn trong các hiệp định thương mại tự do - phần "Quy định FTA về tiêu chuẩn lao động".

2. Tổng Liên đoàn Lao động Việt Nam - FES (Hà Nội, 26/2/2014): Hội thảo quốc tế "Vấn đề lao động và vai trò của công đoàn trong hiệp định thương mại tự do (FTA) EU với các nước".

3. TS. Pham Thị Thu Lan (2020), Thực hiện cam kết về lảo động trong NAFTA: Thực tiến Mexico và bài học cho Viê̂t Nam, NXB Lao động, HN.

4. ThS. Nguyê̂n Ngọc Sơn (2014), Tình hình tổ chức, cán bộ công đoàn chuyên trách công đoàn cấp trên trực tiếp cơ sở, đề xuất một số giải pháp nâng cao nẳng lực hoạt động đáp ứng yêu câu mới

5. Viên Công nhân và Công đoàn (2015), "Đổi mới mô hình tổ chức, nội dung và phương thức hoạt động công đoàn hướng về đoàn viên và NLĐ thời gian tới", Đề tài cấp TLĐ.

6. Viện Công nhân và Công đoàn (2015), "Dự báo tác động tới việc làm, $Q H L \boxminus$ va hoat động công đoàn khi Việt Nam gia nhập các hiệp định thương mại tự do" Đề tài cấp TLĐi. 